\title{
KELIMPAHAN FITOPLANKTON DI PERAIRAN KAWASAN MANGROVE PULAU SANTEN BANYUWANGI
}

\author{
Riatul Fila, N. Nurcahyati, Fuad Ardiyansyah \\ Program Studi Biologi, Fakultas Matematika dan Ilmu Pengetahuan Alam \\ Universitas PGRI Banyuwangi \\ Email: fuad.bio87@gmail.com
}

\begin{abstract}
ABSTRAK
Plankton merupakan suatu organisme yang hidup dengan cara mengapung di permukaan air mengikuti gelombang. Plankton sendiri memiliki kekurangan dalam kemampuan untuk berenang, sehingga gerakannya mengikuti gelombang. Plankton diklompokkan menjadi dua yaitu phytoplanktons dan zooplanktons. Fitoplankton memiliki fungsi penting di perairan. Fungsi mereka tidak hanya sebagai produsen utama tetapi mereka juga sebagai kontrol kualitas perairan. Tujuan dari penelitian ini adalah untuk mendapatkan keanekaragaman mangrove vegetasi fitoplankton yang ada di Pulau Santen Banyuwangi. Penelitian ini telah dilakukan pada bulan April hingga Agustus 2016. Sampel diambil dengan menggunakan metode pusposive sampling, dengan membagi area menjadi 3 stasiun. Stasiun 1 terletak di dekat penduduk sipil, stasiun 2 terletak di tengah perairan, dan stasiun 3 di dekat area hutan bakau. Hasil penelitian ini menunjukkan bahwa terdapat 5 Gen fitoplankton, Chlorella, Eulena, Amphora, Oscillatoria, dan Nitzschia. Chlorella termasuk dalam Chlorophyceace classis, Euglena di Euglenidae, Oscillatoria di Chyanophyceae, Amphora dan Nitzschia di Bacillariophyceae. Keragaman ini didominasi oleh keberadaan Chlorella yang menentukan dalam kekayaan indec 64000 ind / L. Genus Nitzschia dan Amphora ditemukan di setidaknya 160 ind / L. Keragaman fitoplankton sangat dipengaruhi oleh pengukuran lingkungan, seperti suhu air, Ph, salinitas, intensitas cahaya, dan DO.
\end{abstract}

Kata kunci: Keanekaragaman, Fitoplankton, mangrove, Pulau Santen

\begin{abstract}
Planctons organism that live by floating in the surface of water flows by waves. They have less much ability to swim, so their movement are in fluence by waves. There are two groups of planctons that is phytoplanctons and zooplanctons. Phytoplanctons have important functions in the waters. Their functions are not only as primary producer but they are also as a quality control of the waters. The purpose of this research was to obtain the diversity of phytoplanctons vegetation mangrove are in Pulau Santen Banyuwangi. This research has been done in April to August, 2016. The sample were taken using pusposive sampling methode, by devede the area into 3 stations. Stations 1 was locatednear civil resident, station 2 was located in the middle of waters, and station 3 near mangrove area. The result of this research showed that there were 5 Genus of phytoplanctons, Chlorella, Eulena, Amphora, Oscillatoria, and Nitzschia. Chlorella was include in Chlorophyceace classis, Euglena in Euglenidae, Oscillatoria in Chyanophyceae, Amphora and Nitzschia in Bacillariophyceae. This diversity was dominated by Chlorella presence determine in richness indec 64000 ind/L. Genus of Nitzschia and Amphora were
\end{abstract}


found in a few at least $160 \mathrm{ind} / \mathrm{L}$. The diversity of phytoplanctons were very influence by environment measurement, such as water themperature, $\mathrm{Ph}$, salinity, light intensity, and DO.

Keywords: Diversity, Phytoplanctons, Mangrove, Pulau Santen

\section{PENDAHULUAN}

Estuari merupakan salah satu ekosistem pesisir yang produktif dan paling mudah terganggu oleh tekanan lingkungan yang diakibatkan oleh kegiatan manusia (Dahuri et al, 1996). Menurut Odum (1971), estuari adalah badan perairan setengah tertutup yang berhubungan dengan laut terbuka, sehingga sangat dipengaruhi oleh gerakan pasang surut yang menyebabkan terjadinya percampuran air tawar dan air laut. Percampuran dari massa air tersebut dapat menyebabkan fluktuasi parameter fisika dan kimia di perairan estuari. Kondisi lingkungan yang selalu berfluktuasi ini akan mempengaruhi organisme dan biota yang ada di dalam perairan.

Perairan estuari umumnya di tumbuhi oleh vegetasi mangrove seperti, Avicennie marina, Sonneratia alba, Rhyzophora mucronata, Bruguiera gymnorrhiza, Ceriops tagal, Xylocarpus moluccensis, Excoecaria agallocha (Kusuma, C dan Istomo, 1995). Mangrove merupakan suatu ekosistem yang komplek dan khas, serta memiliki daya dukung cukup besar terhadap lingkungan sekitarnya. Fungsi vegetasi mangrove diantaranya yaitu pelindung garis pantai, mencegah intrusi air laut, habitat (tempat tinggal), tempat mencari makan (feeding ground), tempat pemijahan (spawning ground), tempat asuhan dan pembesaran (nursery ground) bagi berbagai jenis ikan, udang, gastropoda, burung dan biota lainnya seperti fitoplankton (Budiman dan Suhardjono, 1992). Fitoplakton merupakan salah satu komponen penting dalam suatu ekosistem karena memiliki kemampuan untuk menyerap energi matahari melalui proses fotosintesis untuk membentuk bahan organik dari bahan-bahan anorganik yang dikenal sebagai produktivitas primer ( Widyorini, 2009 ).

Fitoplankton merupakan organisme renik yang melayang-layang dalam air atau mempunyai kemampuan renang yang sangat lemah dan pergerakannya selalu dipengaruhi oleh pergerakan masa air (Nybakken, 1992). Peran vegetasi mangrove 
terhadap fitoplankton sebagai salah satu produsen pada lingkungan perairan yang memberikan sumbangan terhadap biota peraian sebagai penyuplai nutrien untuk pertumbuahan fitoplankton. Beberapa unsur hara yang dimaksud berupa daun-daun kering, patahan-patahan ranting yang kemudian mengalami dekomposisi dan dimanfaatkan oleh fitoplankton sebagai bahan dalam proses fotosintesis. Kemampuan fitoplankton yang dapat berfotosintesis dan menghasilkan senyawa organik membuat fitoplankton disebut sebagai produsen primer (Prabandani, 2002). Dalam hal ini fitoplankton memegang peran yang sangat penting dalam suatu perairan, yaitu sebagai indikator skala kesuburan suatu perairan pada awal mata rantai dalam jaring-jaring makanan, karena jika kelimpahan fitoplankton di perairan tinggi maka perairan tersebut cenderung memiliki tingkat produktifitas yang tinggi (Handayani, 2008; Raymon, 1980).

Pulau santen merupakan salah satu objek wisata yang terletak di kelurahan Karangrejo Kecamatan Banyuwangi, sebelah selatan stasiun Banyuwangi lama. Pada kawasan Pulau Santen terdapat vegetasi mangrove buatan yang di tanaman oleh warga setempat, karena menurut warga vegatasi mangrove tersebut sangat penting yaitu sebagai tempat hidup dan tempat bertelur hewan maupun organisme yang ada di kawasan vegetasi mangrove tersebut. Salah satunya seperti ikan dan kepiting bakau. Namun kurangnya kesadaran masyarakat akan kebersihan lingkungan menjadikan banyak sampah anorganik terkumpul di perairan estuari mangrove Pulau Santen. Hal ini jelas akan mempengaruhi ekosistem yang ada di sana, mengingat fungsi mangrove sebagai plasma nutfah dan menjaga keseluruhan sistem kehidupan disekitarnya, salah satunya yaitu fitoplankton (Handayani, 2008).

\section{METODE PENELITIAN}

\subsection{Waktu dan Tempat Penelitian}

Penelitian dilakukan pada bulan Juni sampai juli 2016. 
Penelitian dilakukan pada bulan Juni sampai juli 2016 dan lokasi penelitian kelimpahan fitoplankton dilaksanakan di perairan kawasan mangrove Pulau Santen Kelurahan Karangrejo Banyuwangi.

\subsection{Alat dan Bahan}

Alat yang digunakan dalam penelitian ini yaitu, sebagai berikut: Plankton net, botol 30ml (untuk menyimpan smpel fitoplankton), termometer batang, $\mathrm{pH}$ meter digital, hand refractometer, secchi disk, mikroskop, kertas lebel, alat tulis, dan kamera

Bahan yang digunakan dalam penelitian ini yaitu, sebagai berikut: cairan sampel fitoplankton, alkohol $97 \%$ (untuk mengawetkan sampel). Larutan lugol (untuk memperkuat warna fitoplankton).

\subsection{Prosedur Penelitian}

\section{a. Penentuan Stasiun}

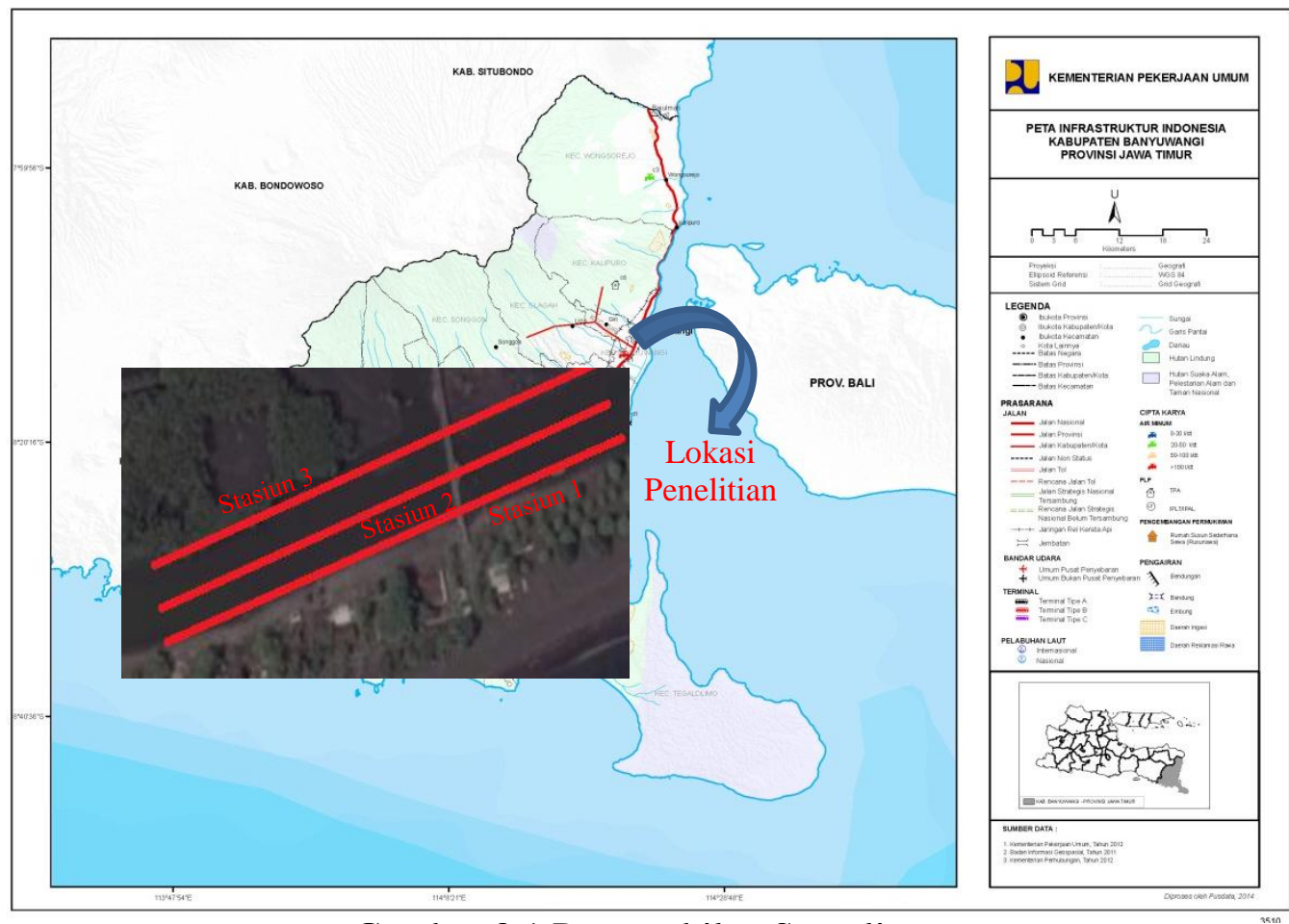

Gambar 3.1 Pengambilan Sampling

(Sumber google earth) 
Pada penelitian ini di tetapkan 3 stasiun dengan 3 titik pengambilan sampel yaitu: 1).Stasiun 1 dekat dengan pemukiman, jarak antara pemukiman dengan stasiun 1 yaitu $5 \mathrm{~m}$ karena jika terlalu dekat dengan pemukiman pengambilan sampel akan sulit, karena banyak sampah terkumpul akibat aktifitas masyarakat sekitar. 2) Stasiun 2 terletak di tengah sungai, karena cahaya yang masuk ke air lebih mudah sehingga memungkinkan fitoplaknton melakuakan fotosintesis. 3) Stasiun 3 terletak di tepi luar kawasan mangrove.

\section{b. Pengambilan Sampel}

Pengambilan sampel pada penelitian ini menggunakan metode purposive sampling, Sebelum Pengabilan sampel fitoplankton dilakukan dengan menentukan titik pengambilan sampel, pengambilan sampel fitoplankton yang ada di permukaan perairan adalah menggunakan plankton net, yaitu dengan cara penyaringan dengan menggunakan ember plastik sebanyak 60 1, sampel air yang telah disaring kemudian di tampung dalam botol sampel 30ml, lalu botol sampel diberi alkohol 97\% (sebagai pengawet), kemudian diberi larutan lugol (untuk memperkuat pewarnaan fitoplankton).

\section{c. Pengumpulan Data}

Tahap ketiga dari prosedur penelitian ini adalah pengumpulan data tanaman. Pengumpulan data dilakukan dengan mencatat setiap nama tanaman yang disebutkan oleh responden, kemudian melihat langsung tanaman yang disebutkan dan dilanjutkan menuliskannya pada tabel perekam data. Pada tahap ini juga dilakukan identifikasi tanaman untuk mengetahui nama ilmiahnya. Dokumentasi tanaman dilakukan untuk memudahkan identifikasi.

\subsection{Analisis Data}

Data yang telah terkumpul kemudian dianalisis secara deskriptif untuk mengetahui kelimpahan fitoplankton di perairan kawasan mangrove pulau santen. Kelimpahan fitoplankton dapat dihitung dengan menggunakan rumus dari Sachlan (1982).

$$
\mathrm{K}: \frac{30}{0,05} \times \frac{18 \times 18}{25} \times \frac{\text { jumlah individu fitoplankton }}{\text { volume air yang disaring }(\text { liter })}
$$


Keterangan :

$\mathrm{K} \quad$ : Kelimpahan ind/ml

30 : Volume air dalam botol sampel (ml)

0,05 : Volume air yang diamati $(\mathrm{ml})$

$18 \times 18$ : Luas gelas penutup $\left(\mathrm{mm}^{2}\right)$

25 : Jumlah lapang pandang

\section{HASIL DAN PEMBAHASAN}

\subsection{Hasil Data}

Berdasarkan hasil penelitian di perairan kawasan mangrove Pulau Santen Banyuwangi di temukan 5 Famili dan 5 Genus fitoplankton, dapat dilihat pada tabel 3.1 berikut ini:

Tabel 3.1. Jenis Fitoplankton Yang ditemukan di Kawasan Mangrove Pulau Santen Banyuwangi

\begin{tabular}{ccccccc}
\hline No & $\begin{array}{c}\text { Fitoplankton } \\
\text { yang } \\
\text { ditemukan }\end{array}$ & Filum & Kelas & Ordo & Famili & Genus \\
\hline 1 & Chlorella & Chlorophyta & Chlorophyceae & Chlorococcales & Chlorellaceae & Chlorella \\
2 & Euglena & Euglenozoa & Euglenidea & Euglenida & Euglenidae & Euglena \\
3 & Amphora & Bacillariophyta & Bacillariophyceae & Pennales & Cymbellaceae & Amphora \\
4 & Oscillatoria & Chyanophyta & Chyanophyceae & Oscillatoriales & Oscillatoriaceae & Oscillatoria \\
5 & Nitzchia & Bacillariophyta & Bacillariophyceae & Bacillariales & Nitzchiaceae & Nitzchia \\
\hline
\end{tabular}

Pada tabel 3.1 dapat dilihat bahwa terdapat 5 genus fitoplankton yang ditemukan yaitu Chlorell, Euglena, Amphora, Oscillatoria, dan Nitzschia. Chlorella merupakan alga bersel tunggal, berukuran mikroskopis, berbentuk bola, berwarna hijau, hal tersebut dikarenakan selnya mengandung klorofil dalam jumlah yang besar. Alga ini biasa hidup dalam air tawar dan terdiri dari banyak ordo, yaitu

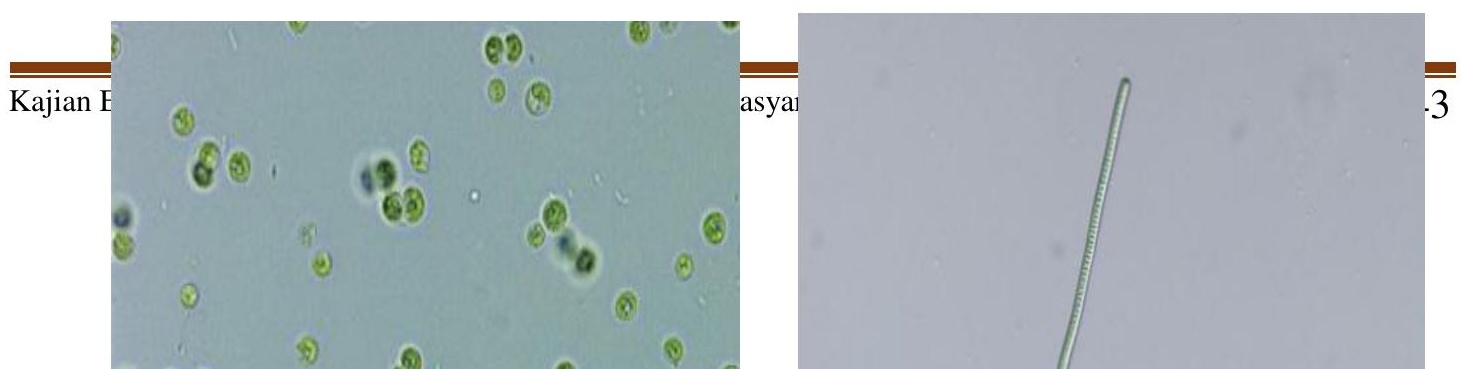


(Gambar: Chlorella) ～(Gambar: Oscillatoria)

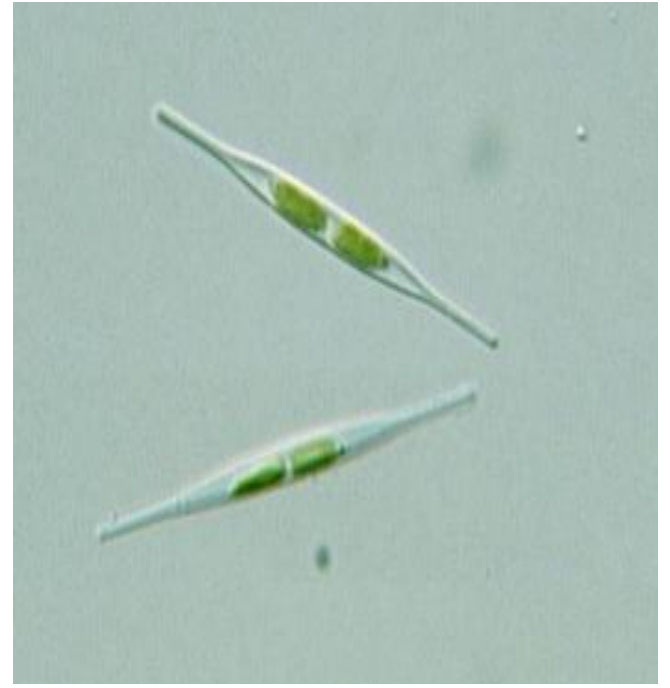

(Gambar: Nitzchia)

Gambar 3.1. Jenis fitoplankton yang ditemukan di kawasan Pulau Santen

Chlorococcales, Ulotrichales, Cladoporales, Volvocales dan Conjugales (Tjitrosoepomo, 1981). Oscillatoria memiliki ciri berbentuk silindris dan tidak bercabang, dan berwarna hijau. Nitzschia memiliki ciri-ciri bentuk sel elips dengan warna kecoklatan sedangkan Amphora memiliki ciri-ciri berbentuk batang seperti perahu. Euglena memiliki ciri bentuk sel oval memanjang memiliki flagel untuk 
bergerak dan berwarna hijau (Isnansetyo dan Kurniastuty, 1995). Euglena banyak hidup di tempat yang banyak mengandung bahan organik. Hidupnya soliter, tidak pernah membentuk koloni. Kloroplas berbentuk cakram sampai bentuk pita (Erdiana D dkk, 2013).

\section{a. Kelimpahan Fitoplankton}

Berdasarkan hasil penelitian di perairan kawasan mangrove pulau santen Banyuwangi kelimpahan fitoplankton dapat dilihat pada tabel berikut.

Tabel 3.2 Kelimpahan Fitoplankton di Perairan Kawasan Mangrove Pulau Santen

\begin{tabular}{clcccccc}
\hline No & $\begin{array}{c}\text { Jenis } \\
\text { Fitoplankton }\end{array}$ & St 1 & St 2 & St 3 & Rata-rata & $\begin{array}{c}\text { Jumlah } \\
\text { Total }\end{array}$ & $\begin{array}{c}\text { Kelimpahan } \\
\text { (ind/L) }\end{array}$ \\
\hline 1 & Chlorella & 131 & 138 & 131 & 133.3 & 400 & 64000 \\
2 & Euglena & 8 & 19 & 0 & 13.5 & 30 & 4800 \\
3 & Amphora & 1 & 0 & 0 & 1.0 & 1 & 160 \\
4 & Oscillatori & 2 & 0 & 0 & 2.0 & 2 & 320 \\
5 & Nitzschia & 0 & 0 & 1 & 1.0 & 1 & 160 \\
& Jumlah & 142 & 157 & 132 & 150.8 & 431 & 68960 \\
\hline
\end{tabular}

Ket : St 1-3 : Stasiun 1-3

Pada Tabel 3.2 dapat dilihat bahwa kelimpahan fitoplankton tertinggi yaitu dari jenis Chlorella dengan kelimpahan 64000 ind/L, sedangkan kelimpahan fitoplankton terendah yaitu dari jenis Amphora dan Nitzschia, dengan kelimpahan 160 ind/L.

\section{b. Parameter Lingkungan}

Parameter lingkungan yang di ukur pada penelitian ini yaitu suhu, $\mathrm{pH}$ Air, salinitas, kecerahan, dan oksigen terlarut (DO). Berdasarkan hasil pengukuran parameter lingkungan yang diperoleh di perairan kawasan mangrove Pulau Santen dapat di lihat pada tebel berikut:

Tabel 3.3 Hasil Pengukuran Parameter Lingkungan

\begin{tabular}{cccccccc}
\hline No & $\begin{array}{c}\text { Prameter } \\
\text { Lingkungan }\end{array}$ & Satuan & St 1 & St 2 & St 3 & Rata-rata & $\begin{array}{c}\text { Standar } \\
\text { deviasi }\end{array}$ \\
\hline 1 & Suhu & C & 30.3 & 29 & 29.3 & 29.5 & 0.68
\end{tabular}




\begin{tabular}{clcccccc}
\hline \hline 2 & $\mathrm{pH}$ & - & 7 & 7 & 7 & 7.0 & 0.00 \\
3 & Salinitas & $\mathrm{Ppm}$ & 31.3 & 33 & 32.7 & 32.3 & 0.91 \\
4 & Kecerahan & $\mathrm{cm}$ & 121.6 & 154.9 & 129.8 & 135.4 & 17.35 \\
& Oksigen & & & & & & \\
5 & Terlarut (DO) & $\mathrm{mg} / \mathrm{L}$ & 5.82 & 6.07 & 5.87 & 5.9 & 0.13 \\
\hline
\end{tabular}

Pada tabel 3.3 menunjukkan bahwa nilai rata-rata parameter lingkungan yang ada di perairan kawasan mangrove pulau santen yaitu suhu berkisar antara $29.5^{\circ} \mathrm{C}, \mathrm{pH}$ 7, salinitas 32,3 ppm, kecerahan 135,4 $\mathrm{cm}$ dan oksigen terlarut berkisar antara 5,9 $\mathrm{mg} / \mathrm{L}$.

\section{Pembahasan}

Berdasarkan hasil analisis dari Tabel 4.1 terdapat 5 jenis fitoplankton yaitu Chlorell, Euglena, Amphora, Oscillatoria, dan Nitzschia. Chlorella termasuk kedalam kelas Chlorophyceae. Chlorophyceae merupakan ganggang hijau. mempunyai kloroplas yang mengandung klorofil a, klorofil b dan karotinoid. Chlorophyceae terdiri dari sel-sel kecil yang membentuk koloni berupa benang bercabang atau tidak bercabang, ada juga membentuk koloni yang menyerupai kormus tumbuhan tinggi. Alga ini biasa hidup dalam air tawar dan terdiri dari banyak ordo, yaitu Chlorococcales, Ulotrichales, Cladoporales, Volvocales dan Conjugales (Tjitrosoepomo, 1981). Oscillatoria termasuk kedalam kelas chyanophyceae. Cyanophyceae banyak ditemukan pada perairan yang tercemar berat, terutama pada pembuangan limbah industri yang kurang mendapat cahaya matahari. Cyanophyceae terdiri dari +150 spesies yang berasal dari beberapa family, yaitu Oscilatoriaceae, Nostacaceae, Rivulariaceae, Chroococeae, Notochopcideae dan Scytonemataceae (Sachlan, 1974).

Nitzschia dan Amphora termasuk kedalam kelas Bacillariophyceae. Bacillariophyceae adalah salah satu kelompaok alga yang secara kualitatif dan kuantitatif banyak terdapat di berbagai tipe perairan, baik sebagai plankton maupun sebagai perifiton Bacillariophyceae atau Diatomae disebut juga dengan ganggang kersik, berupa jasad renik bersel satu yang masih dekat dengan Flagellatae. Diatomae 
hidup dalam air tawar maupun dalam air laut, serta di atas tanah-tanah yang basah, terpisah-pisah atau membentuk koloni (Tjitrosoepomo, 1981). Lisanti (2000), menyatakan bahwa kelas Bacillariophyceae merupakan kelompok alga yang mudah beradaptasi dengan lingkungan dan penyebarannya luas, serta merupakan bagian terpenting dari organisme air karena merupakan makanan bagi zooplankton atau hewan air lainnya, sedangkan Chlorophyceae yang termasuk ke dalam filum Chlorophyta paling banyak dijumpai di perairan tawar (Adjie, et al 2003).

Mikro alga membutuhkan cahaya untuk fotosintesis dalam fase fotokimia untuk menghasilkan ATP dan NADPH, sedangkan untuk fase biokimia yaitu sintesis molekul esensial untuk pertumbuhannya tidak memerlukan cahaya (tanpa adanya cahaya) (Al-Qasmi, at al. 2012).

Pada Tabel 4.2 jumlah kelimpahan fitoplankton banyak di temukan dari jenis Chlorella hal ini dikarenakan Chlorella bersifat komposlit dan dapat tumbuh dimanamana. Tingginya kelimpahan pada Chlorella karena dipengaruhi oleh faktor lingkungan yang mendukung seperti kecerahan, suhu, salinitas dan Oksigen terlarut (DO). Chlorella dapat tumbuh pada salinitas 0-35\% . salinitas 10-20\%o merupakan salinitas optimum untuk pertumbuhan Chlorella. Suhu optimum untuk pertumbuhan Chlorella adalah $25-30^{\circ} \mathrm{C}$ (Isnansetyo dan Kurniastuty, 1995).

Kelimpahan fitoplankton di perairan kawasan mangrove pulau santen pada pengamatan antar stasiun berbeda hal ini dikarena keadaan lingkungan sekitar stasiun yang mepengaruhi keberadaan fitoplankton. Kelimpahan fitoplankton pada stasiun 2 lebih tinggi dibandingkan dengan stasiun 1 dan 3. Hal tersebut dikarenakan stasiun 2 terletak di tengah perairan, permukaan perairan pada stasiun ini cukup terbuka dibanding stasiun lainnya serta airnya lebih jernih, sehingga badan air mendapat cahaya matahari yang cukup sampai ke dasar perairan dan cahaya matahari ini sangat dibutuhkan oleh fitoplankton untuk fotosintesis. Karena intensitas cahaya matahari yang masuk keperairan lebih optimal, sehingga proses fotosintesis fitoplankton dapat berjalan maksimal (Suryanto, 2011). Sedangkan stasiun 1 terletak dekat dengan 
pemukiman, hal itu dapat mempengaruhi keberadaan fitoplankton salah satunya dari aktifitas penduduk sekitar yang menghasilkan limbah domestik dari sisa rumah tangga yang di buang ke perairan pulau santen, maupun akibat dari sampah domestik yang menumpuk pada saat pasang. Sehingga mengakibatkan keruhnya perairan, sehingga terjadi penurunan kelimpahan fitoplankton. Murrel et al. (2007) menyatakan bahwa tingginya kekeruhan di perairan estuari karena adanya partikel tersuspensi yang dapat membatasi produktivitas fitoplankton pada suatu perairan. Sedangkan pada stasiun 3 keberadaan fitoplankton sedikit karena stasiun 3 terletak dekat dengan mangrove. Hal itu mengakibatkan cahaya yang masuk ke perairan terhalang oleh mangrove sehingga manghambat proses fotosintesis (Sutomo, 2013). Menurut Nybakken (1988) fotosintesis hanya dapat berlangsung bila intensitas cahaya yang sampai ke suatu sel alga lebih besar dan laju fotosintesis akan tinggi bila intensitas cahaya tinggi dan menurun bila cahaya menurun.

\section{KESIMPULAN DAN SARAN}

\subsection{Kesimpulan}

Berdasarkan hasil penelitian, dapat diambil kesimpulan sebagai berikut:

a. Pada penelitian ini di temukan 5 jenis fitoplankton yaitu Chlorella, Euglena, Amphora, Oscillatoria, dan Nitzchia. Yang termasuk kedalam kelas Chlorophyceae, Bacillariophyceae, dan Chyanophyceae

b. Kelimpahan fitoplankton terdapat pada stasiun 2 yaitu di tengah perairan yang di dominasi oleh jenis Chlorella dengan jumlah kelimpahan 25120 ind/L dan kelimpahan fitoplaktom terendah terdapat pada stasiun 3 dengan jumlah kelimpahan 21120 ind/L.

\subsection{Saran}

Perlu dilakukan penelitian lebih lanjut tentang hubungan kelimpahan fitoplankton dengan parameter lingkungan di perairan kawasan hutan mangrove pulau santen . 


\section{REFERENSI}

Adjie,S., Samuel., \& Subagja., 2003. Kelimpahan dan Keragaman Plankton di Danau Arang-Arang, Jambi. Jurnal Penelitian Perikanan Indonesia Volume 9(7): 1-7.

Al-Qasmi, M., Raut. N., Talebi. S., Al-Rajhi, S., Al-Barwani. T. 2012. A review of Effect of Light on Microalgae Growth. Prceedings of the world congress on engineering, WCE. Vol 1

Dahuri, R, J. Rais, S.P. Ginting dan M.J. Sitepu. 1996. Pengelolaan Sumber Daya Pesisir dan Lautan Secara Terpadu. PT Pradnya Paramita. Jakarta.

Handayani dan Diana, 2005. Pengantar Planktonologi (fitoplankton). Wuffic.ub

Lisanti. 2000. Distribusi Plankton Disungai Jujuhan Desa Batu Kangkung Taman Nasional Kerinci Seblat Kabupaten Sawahlunto Sijunjung Propinsi Sumatera Barat.

Murrel, M. C., Haqy III, J. D., Emile., Lores, M., Greene, R. M. 2007. Phytoplankton Production and Nutrient Distributions in a Subtropical Estuary: Importance of freshwater Flow. Estuaries and Coasts,30(3): 390-402.

Nybakken, J. W. 1992. Biologi Laut. Suatu Pendekatan Ekologis Terjemahan dari Marine Biology: An Ecological Approach. Alih Bahasa: M. Eidman Koesoebiono, D. G. Bengen dan M. Hutomo. Gramedia, Jakarta. 459p.

Odum, E.P. 1971. Fundamentals of Ecology. Third edition. W.B. Saunders Company, Philadelphia, London, Toronto, 574 pp.

Prabandani, D. 2002. Struktur Komunitas Fitoplankton di Teluk Semangka, 
Raymont, J.E.G, 1980. Plankton and productivity in the ocean. 2nd ed. Pergamon Press. New York. 824p.

Sachlan, M. 1982. Planktonologi. Semarang : Fakultas Peternakan dan Perikanan Universitas Diponegoro.

Sutomo. 2013. Struktur Komunitas Fitoplankton di Perairan Teluk Sekotong dan Teluk Kodek, Kabupaten Lombok. Jurnal Ilmu dan Teknologi Kelautan Tropis, Vol. 5, No. 1

Tjirosoepomo, G. 1981. Taksonomi Tumbuhan Khusus. Bhatara Aksara, Jakarta.

Widyorini, N. 2009. Pola Struktur Komunitas Fitoplankton Berdasarkan Kandungan Pigmennya di Pantai Jepara. 